\title{
Inter- and Intra-Observer Variability for Assessment of the Synergy Between Percutaneous Coronary Intervention With TAXUS and Cardiac Surgery (SYNTAX) Score and Association of the SYNTAX Score With Clinical Outcome in Patients Undergoing Unprotected Left Main Stenting in the Real World
}

\author{
Hiroki Shiomi, MD; Toshihiro Tamura, MD; Shunichiro Niki, MD; Tomohisa Tada, MD; \\ Junichi Tazaki, MD; Masanao Toma, MD; Koh Ono, MD; Tetsuo Shioi, MD; \\ Takeshi Morimoto, MD; Masaharu Akao, MD; Yutaka Furukawa, MD; \\ Yoshihisa Nakagawa, MD; Takeshi Kimura, MD
}

\begin{abstract}
Background: The Synergy Between Percutaneous Coronary Intervention With TAXUS and Cardiac Surgery (SYNTAX) score was proposed as a method to evaluate the complexity of coronary anatomy. However, the reproducibility of assessment for the SYNTAX score in unprotected left main coronary artery (ULMCA) disease has not yet been adequately evaluated. The purpose of this study is to assess inter- and intra-observer variability for the assessment of the SYNTAX score in patients undergoing ULMCA stenting in daily clinical practice.
\end{abstract}

\begin{abstract}
Methods and Results: The SYNTAX score of 101 consecutive patients who underwent ULMCA stenting with sirolimus-eluting stent was independently assessed by 2 experienced interventional cardiologists. One of the 2 cardiologists evaluated all the cases again 6 months after the initial assessment. The $\kappa$ value for inter-observer variability in estimating the SYNTAX score was 0.62 according to the dichotomized analysis $(\geq 33,<33)$ and 0.58 according to the tertile analysis $(<23,23 \leq-<33, \geq 33)$, while the intra-observer variability was 0.78 and 0.69 , respectively. Patients with a high SYNTAX score $(\geq 33, n=55)$ compared with those with low or intermediate score $(<33, n=46)$ had a significantly higher rate of target-lesion revascularization (TLR) of the ULMCA lesion at 2 years (24\% vs. $4.4 \%, P=0.01)$.
\end{abstract}

Conclusions: Both inter- and intra-observer variability for estimating the SYNTAX score were within an acceptable range and a high SYNTAX score showed a higher rate of TLR in patients undergoing ULMCA stenting in daily clinical practice. (Circ J 2011; 75: 1130-1137)

Key Words: Coronary disease; Percutaneous coronary intervention; Revascularization; SYNTAX score

$\mathbf{P}$ ercutaneous coronary intervention (PCI) has been considered as a contraindication in patients with unprotected left main coronary artery (ULMCA) disease. Recently, however, several studies reported favorable clinical outcomes in patients undergoing ULMCA stenting using a drug-eluting stent. ${ }^{1-7}$ Therefore, PCI with drug-eluting stent for left main disease is emerging as a possible alternative treatment for coronary artery bypass grafting (CABG). However, appropriate criteria in selecting coronary revascularization procedures, such as PCI or CABG, has not been established in patients with ULMCA disease. The Synergy Between Percutaneous Coronary Intervention With TAXUS

Received November 4, 2010; revised manuscript received January 4, 2011; accepted January 26, 2011; released online March 30, 2011 Time for primary review: 32 days

Department of Cardiovascular Medicine, Graduate School of Medicine, Kyoto University, Kyoto (H.S., S.N., T. Tada, J.T., K.O., T.S., T.K.); Division of Cardiology, Tenri Hospital, Tenri (T. Tamura, Y.N.); Division of Cardiology, Hyogo Prefectural Amagasaki Hospital, Amagasaki (M.T.); Center for Medical Education and Clinical Epidemiology Unit, Graduate School of Medicine, Kyoto University, Kyoto (T.M.); Division of Cardiology, Kyoto Medical Center, National Hospital Organization, Kyoto (M.A.); and Division of Cardiology, Kobe City Medical Center General Hospital, Kobe (Y.F.), Japan

No grant.

Mailing address: Takeshi Kimura, MD, Department of Cardiovascular Medicine, Graduate School of Medicine, Kyoto University, 54 Shogoin Kawahara-cho, Sakyo-ku, Kyoto 606-8507, Japan. E-mail: taketaka@kuhp.kyoto-u.ac.jp

ISSN-1346-9843 doi: 10.1253/circj.CJ-10-1112

All rights are reserved to the Japanese Circulation Society. For permissions, please e-mail: cj@j-circ.or.jp 
and Cardiac Surgery (SYNTAX) score was proposed as a method to evaluate the complexity of coronary anatomy. ${ }^{8,9}$ In the SYNTAX trial, the SYNTAX score has shown good discriminative ability between patients suitable for either CABG or PCI, and the reproducibility of estimation of the SYNTAX score has indicated an acceptable degree of agreement. ${ }^{9,10}$ However, the reproducibility of estimation for the SYNTAX score and the predictive ability of the SYNTAX score for clinical outcome have not yet been adequately evaluated in real world clinical practice.

The aim of this study was to evaluate inter- and intraobserver variability for estimating the SYNTAX score in patients undergoing ULMCA stenting with sirolimus-eluting stent (SES) in real world clinical practice. As an exploratory analysis, 2-year clinical outcomes were also assessed according to the SYNTAX score.

\section{Methods}

\section{Patient Population}

The study population consisted of 101 consecutive patients who underwent PCI with SES for de novo ULMCA disease at Kyoto University Hospital between September 2004 and December 2008. The left main coronary artery lesion was regarded as unprotected if there was no patent bypass graft to the left anterior descending coronary artery or left circumflex coronary artery. PCI was performed in patients who preferred PCI rather than $\mathrm{CABG}$ and in patients who were considered to have an unacceptably high risk for CABG. All procedures, including stenting techniques, were left to the discretion of the operators. The recommended antiplatelet regimen included aspirin $(81 \mathrm{mg} /$ day $)$ indefinitely and thienopyridine ( $200 \mathrm{mg}$ of ticlopidine or $75 \mathrm{mg}$ of clopidogrel daily) for at least 3 months. The loading dose and the duration of dual-antiplatelet therapy was left to the discretion of each attending physician.

Written informed consent on the procedure and follow-up protocol was obtained from all patients before the procedure was carried out. The study protocol was approved by the ethical committee of Kyoto University.

\section{Calculation of the SYNTAX Score and Assessment for Inter- and Intra-Observer Variability}

The SYNTAX score was calculated by using the SYNTAX score calculator (available at http://www.syntaxscore.com). The total SYNTAX score was composed of the individual scores for each separate lesion with a diameter stenosis of $\geq 50 \%$ in a vessel of $\geq 1.5 \mathrm{~mm}$ in diameter by visual assessment. The details of the SYNTAX score calculation were previously reported. ${ }^{9}$

To assess inter-observer variability, the SYNTAX score was calculated independently by 2 experienced interventional cardiologists, who were blinded to the procedural results and clinical outcomes. Furthermore, one of the 2 observers calculated all the cases again 6 months after the initial calculation to assess intra-observer variability. The observer was blinded to the results of the initial calculation.

\section{Evaluation of the Correlation Between SYNTAX Score and Clinical Outcomes}

As an exploratory analysis, 2-year clinical outcomes were also assessed according to the SYNTAX score. To assess the correlation between SYNTAX score and clinical outcomes, we divided the patients into 2 groups: low-intermediate score group (SYNTAX score <33) and high score group (SYNTAX

\begin{tabular}{|c|c|}
\hline$\kappa$ value & Degree of agreement \\
\hline$<0.01$ & Less than chance agreement \\
\hline $0.01-0.20$ & Slight agreement \\
\hline $0.21-0.40$ & Fair agreement \\
\hline $0.41-0.60$ & Moderate agreement \\
\hline $0.61-0.80$ & Substantial agreement \\
\hline $0.81-0.99$ & Almost perfect agreement \\
\hline
\end{tabular}

score $\geq 33$ ). The cutoff point of 33 was set according to the SYNTAX trial result, which suggested that compared with CABG, PCI was associated with a higher rate of major cardiac and cerebrovascular events (MACCE) in patients with a SYNTAX score of $\geq 33$, but not in patients with a SYNTAX score of $<33 .{ }^{8}$ In the case of disagreement between observers on the assessment of the SYNTAX score, the decision of a third observer was obtained after the assessment of interand intra-observer variability was completed.

Data on clinical, lesion, and procedural characteristics were obtained from medical records. Follow-up information was obtained either from a review of the hospital record or by telephone contacts with the patients, the family members, or the primary care physician.

The endpoints assessed included all-cause death, cardiac death, sudden cardiac death, myocardial infarction (MI), stent thrombosis (ST), stroke, target lesion revascularization (TLR), and any coronary revascularization. Two combined endpoints were also assessed including a composite of death, MI, or stroke, and a composite of death, MI, stroke, or any coronary revascularization (MACCE). Death was regarded as cardiac in origin unless obvious non-cardiac causes could be identified. MI was adjudicated according to the definition in the Arterial Revascularization Therapy Study. ${ }^{10} \mathrm{ST}$ was defined according to the Academic Research Consortium (ARC) definition. ${ }^{11}$ Stroke was defined as a symptomatic cerebrovascular event confirmed by imaging studies. TLR was defined as either PCI or CABG due to restenosis or thrombosis of the ULMCA lesion that included the proximal and distal edge segments as well as the ostium of the side branches.

\section{Statistical Analysis}

Continuous variables were expressed as mean \pm SD unless otherwise indicated and were compared with Student's t-test or Wilcoxon rank sum test on the basis of their distribution. Categorical variables were presented as numbers and/or percentages, and were compared with the chi-square test or Fisher's exact test, as appropriate. Cumulative incidences of adverse events were estimated by the Kaplan-Meier method and compared using the log-rank test.

The degree of agreement was measured as a percentage of the total agreement using the $\kappa$ statistic to evaluate inter- and intra-observer variability. The $\kappa$ statistic is the most commonly used statistic for the evaluation of an agreement between 2 or more observations. ${ }^{12} \mathrm{~A} \kappa$ value of 1 means perfect agreement, whereas a $\kappa$ value of 0 means agreement equivalent to chance. The quantitative classification of the $\kappa$ value is shown in Table $\mathbf{1 .}^{12-14}$ The $\kappa$ statistic was calculated for the SYNTAX score dichotomies $(<33, \geq 33)$, and for the tertiles $(<23,23 \leq-<33, \geq 33)$. Regarding the components of scoring, the $\kappa$ values for the presence of ostial lesion, true bifurcation, long lesion, and severe calcification in the ULMCA lesions were also evaluated.

All statistical tests were 2-tailed. P-values of less than 0.05 
A Inter-observer variability

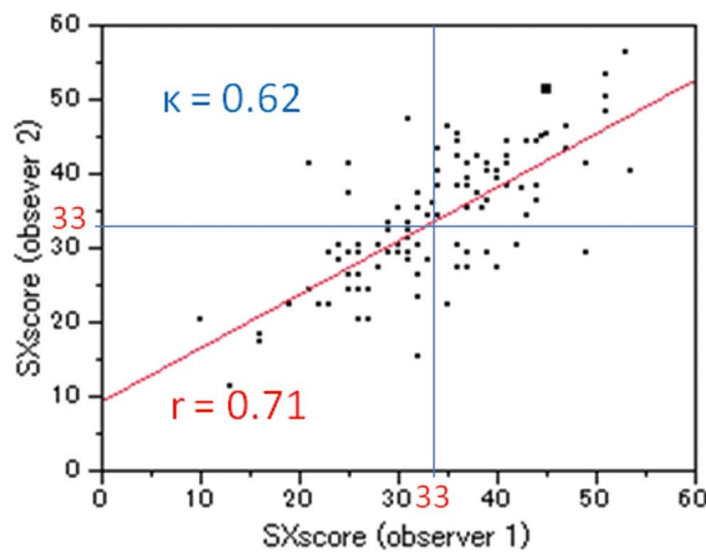

SYNTAX score

Observer 1 34.1 \pm 8.8 (range 10-53.5)

Observer $233.8 \pm 8.6$ (range 11-56)
B Intra-observer variability

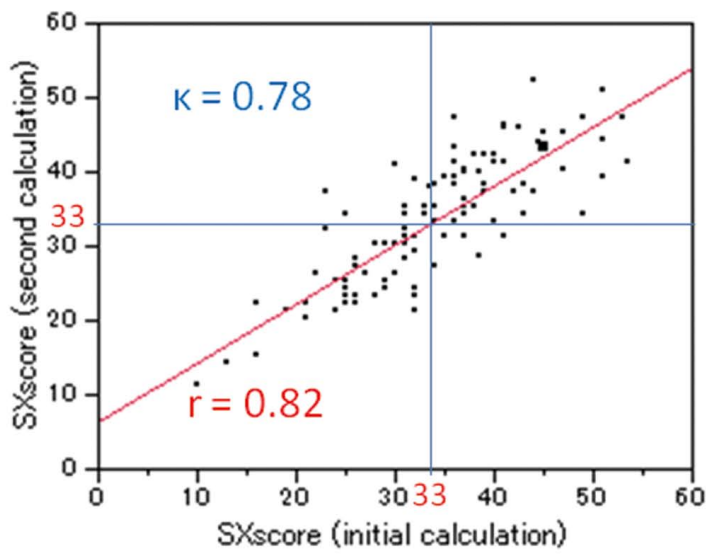

SYNTAX score

Initial calculation $34.1 \pm 8.8$ (range 10-53.5)

Second calculation $33.4 \pm 8.5$ (range 11-52)

Figure 1. Inter- and intra-variability of the Synergy Between Percutaneous Coronary Intervention With TAXUS and Cardiac Surgery (SYNTAX) score. Both inter-observer variability (A) and intra-observer variability (B) showed a moderate to substantial degree of agreement beyond chance. The values of the SYNTAX score are shown as mean \pm SD. $\kappa, \kappa$ value; r, correlation coefficient.

\begin{tabular}{|c|c|c|c|c|c|}
\hline & Initial calculation & Inter-observer & $\kappa$ value & Intra-observer & $\kappa$ value \\
\hline Total SYNTAX score $($ mean $\pm S D)$ & $34.1 \pm 8.8$ & $33.8 \pm 8.6$ & - & $33.4 \pm 8.5$ & - \\
\hline Dichotomies (Low-Intermediate/High: \%) & $45 / 56(45 / 55)$ & $46 / 55(46 / 54)$ & 0.62 & $44 / 57(44 / 56)$ & 0.78 \\
\hline Tertiles (Low/Intermediate/High: \%) & 8/37/56 (8/37/55) & $11 / 35 / 55(11 / 35 / 54)$ & 0.58 & $14 / 30 / 57(14 / 30 / 56)$ & 0.69 \\
\hline \multicolumn{6}{|l|}{ Components of scoring in left main lesion } \\
\hline True bifurcation & $54(53 \%)$ & $59(58 \%)$ & 0.50 & $59(58 \%)$ & 0.74 \\
\hline Aorto ostial lesion & $17(17 \%)$ & $18(18 \%)$ & 0.48 & $12(12 \%)$ & 0.56 \\
\hline Long lesion (>20 mm) & $65(64 \%)$ & $55(54 \%)$ & 0.23 & $68(67 \%)$ & 0.27 \\
\hline Severe calcification & $48(48 \%)$ & $21(21 \%)$ & 0.12 & $61(60 \%)$ & 0.47 \\
\hline
\end{tabular}

Values are mean $\pm \mathrm{SD}$ or $\mathrm{n}(\%)$.

were considered statistically significant. Statistical analysis was performed with JMP 7.0.1 software (SAS Institute Inc, Cary, NC, USA).

The authors had full access to the data and took responsibility for its integrity. All authors have read and agreed to the manuscript as written.

\section{Results}

\section{Variability for Assessment of the SYNTAX Score}

Inter-Observer Variability The mean SYNTAX score calculated by Observer 1 was $34.1 \pm 8.8$ (range 10-53.5), whereas that calculated by Observer 2 was $33.8 \pm 8.6$ (range 11-56) (Figure 1A). The mean difference in the SYNTAX score between the 2 observers was $4.7 \pm 6.6$. The $\kappa$ values in the evaluation of inter-observer variability were 0.62 for the SYNTAX score dichotomies $(<33, \geq 33)$, and 0.58 for the SYNTAX score tertiles $(<23,23 \leq-<33, \geq 33)$. Regarding the components of scoring, the $\kappa$ values for the evaluation of inter-observer variability were 0.48 for ostial lesion, 0.50 for true bifurcation, 0.23 for long lesion and 0.12 for severe calcification (Table 2)

Intra-Observer Variability The mean SYNTAX scores in the first and second calculation performed by Observer 1 were

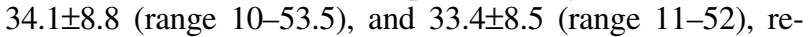
spectively (Figure 1B). The mean difference in the SYNTAX score between the first and second calculation was 4.0 \pm 5.2 . The $\kappa$ value for the evaluation of intra-observer variability was 0.78 for the SYNTAX score dichotomies $(<33, \geq 33)$, and 0.69 for the SYNTAX score tertiles $(<23,23 \leq-<33, \geq 33)$. Regarding the components of scoring, the $\kappa$ values for the evaluation of intra-observer variability were 0.56 for ostial lesion, 0.74 for true bifurcation, 0.27 for long lesion, and 0.47 for severe calcification (Table 2 ).

\section{SYNTAX Score and Clinical Outcomes}

Baseline Characteristics Among 101 consecutive patients undergoing ULMCA stenting with SES, 46 patients had a low-intermediate SYNTAX score and 55 patients had a high SYNTAX score. The mean SYNTAX score was $40.6 \pm 5.4$ in the high score group and $26.3 \pm 5.3$ in the low-intermediate score group. 
Table 3. Patient, Lesion, and Procedural Characteristics

\section{Characteristics}

(A) Patient characteristics

Age (years)

Age $\geq 80$ years, $\%$

Female gender, \%

Body mass index $\geq 25$, \%

Ejection fraction

Ejection fraction $<30 \%$, \%

Heart failure, \%

Prior myocardial infarction, \%

Prior percutaneous coronary intervention, \%

Angina pectoris (symptom), \%

ACS, \%

Diabetes mellitus, \%

History of hypertension, \%

Dyslipidemia, \%

Current smoker, \%

Chronic kidney disease (GFR <30), \%

Dialysis, \%

\section{(B) Lesion characteristics}

Distal bifurcation involvement, \%

Left dominance, \%

Extent of coronary artery disease

Isolated ULMCA, \%

ULMCA + 1 vessel disease, \%

ULMCA + 2 vessel disease, $\%$

ULMCA + 3 vessel disease, \%

Total occlusion, \%

Total SYNTAX score

(C) Procedural characteristics

Number of stents implanted (per patient)

Total stent length, $\mathrm{mm}$ (per patient)

Stent diameter/left main, $\mathrm{mm}$

Elective two-stent, \%

Two-stent (final), \%

Two-stent technique

Classical T stenting, \%

Modified T stenting, \%

Crash stenting, \%

Cullote stenting, \%

$Y$ stenting, \%

Final kissing balloon technique, \%

Values are percentages or mean $\pm S D$

ACS, acute coronary syndrome; GFR, glomerular filtration rate $\left(\mathrm{ml} \cdot \mathrm{min}^{-1} \cdot 1.73 \mathrm{~mm}^{-1}\right)$.

\section{Low-intermediate}

SYNTAX score

$(n=46)$

$71.0 \pm 10.0$

17

22

26

$58.1 \pm 15.3$

4.8

8.7

13

35

63

13

41

74

65

22

11

6.5

76

35

11

41

39

8.7

2.2

$26.3 \pm 5.3$

2. $1 \pm 1.1$

$45.3 \pm 29.4$

$3.5 \pm 0.1$

8.7

11

8.7

0

2.2

0

0

82 $(n=55)$
YNTAX score

$\underset{(n=55)}{\text { SYNTAX score }} \quad$ P value

$71.4 \pm 9.7 \quad$ NS

20 NS

20 NS

$31 \quad$ NS

$58.1 \pm 13.4 \quad N S$

$2.0 \quad$ NS

16 NS

20 NS

$31 \quad$ NS

$78 \quad 0.09$

13 NS

$56 \quad$ NS

$62 \quad$ NS

64 NS

20 NS

13 NS

$9.1 \quad$ NS

$96 \quad 0.02$

$35 \quad$ NS

$<0.001$

1.8

9.1

62

27

22

0.001

$40.6 \pm 5.4<0.001$

$3.7 \pm 1.6<0.001$

$88.3 \pm 39.0<0.001$

$3.5 \pm 0.1 \quad$ NS

$22 \quad 0.07$

$31 \quad 0.01$

0.04

18

7.3

1.8

0

3.6

75

NS
Although there was no significant difference in baseline clinical characteristics between the 2 groups, the high SYNTAX score group tended to have more patients with heart failure and diabetes. The high SYNTAX score group had a higher prevalence of left main distal bifurcation lesions, and multi-vessel coronary artery disease. The total number of stents and total stent length per patient were significantly greater in the high SYNTAX score group than in the lowintermediate SYNTAX score group. The 2-stent technique (stenting of both main- and side-branches) was more frequently used in the high SYNTAX score group than in the low-intermediate SYNTAX score group (Table 3).

\section{Clinical Outcomes}

Angiographic success was obtained $100 \%$ in both groups. The mean clinical follow-up period was $794 \pm 315$ days, and the clinical follow-up rate was $99.0 \%$ at 1 year and $93.1 \%$ at 2 years. Angiographic follow-up was performed in $82.2 \%$ of patients.

There was no significant difference in the rate of any clinical events between the 2 groups at the time of hospital discharge (Table 4). There was also no difference in the incidence of all-cause death and cardiac death within the 2 years between the low-intermediate score group and the high score group ( $15 \%$ vs. $9.2 \%, \mathrm{P}=0.36$ and $3.0 \%$ vs. $7.3 \%$, 
Table 4. Clinical Outcome at Hospital Discharge and After 2 Years

\section{Characteristic}

At hospital discharge

All-cause death

Cardiac death

Sudden cardiac death

Myocardial infarction

Stent thrombosis (definite)

Stroke

Target lesion revascularization

Any revascularization

Death/MI/stroke

MACCE

At 2 years after procedure

All-cause death

Cardiac death

Sudden cardiac death

Myocardial infarction

Stent thrombosis (definite)

Stroke

Target lesion revascularization

Any revascularization

Death/MI/stroke

MACCE

Values are $n(\%)$

MI, myocardial infarction; MACCE, major adverse cardiac or cerebrovascular event.
$\mathrm{N}$ of events (Incidence)

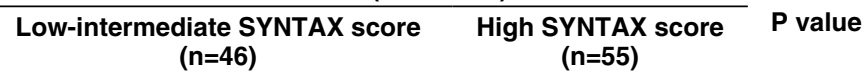

\begin{tabular}{lcc}
$1(2.2 \%)$ & $1(1.8 \%)$ & NS \\
$0(0 \%)$ & $1(1.8 \%)$ & NS \\
$0(0 \%)$ & $0(0 \%)$ & NS \\
$1(2.2 \%)$ & $1(1.8 \%)$ & NS \\
$0(0 \%)$ & $1(1.8 \%)$ & NS \\
$1(2.2 \%)$ & $0(0 \%)$ & NS \\
$0(0 \%)$ & $1(1.8 \%)$ & NS \\
$0(0 \%)$ & $1(1.8 \%)$ & NS \\
$3(6.5 \%)$ & $2(3.6 \%)$ & NS \\
$3(6.5 \%)$ & $2(3.6 \%)$ & NS \\
$6(15 \%)$ & & \\
$1(3.0 \%)$ & $5(9.2 \%)$ & NS \\
$0(0 \%)$ & $4(7.3 \%)$ & NS \\
$2(5.3 \%)$ & $2(3.7 \%)$ & NS \\
$1(3.0 \%)$ & $3(6.0 \%)$ & NS \\
$4(9.1 \%)$ & $2(4.1 \%)$ & NS \\
$2(4.4 \%)$ & $2(3.8 \%)$ & NS \\
$5(11 \%)$ & $12(24 \%)$ & 0.01 \\
$8(19 \%)$ & $14(28 \%)$ & 0.07 \\
$12(28 \%)$ & $8(15 \%)$ & NS \\
& $19(36 \%)$ & NS \\
\hline
\end{tabular}

$19(36 \%)$ 
A Target Lesion Revascularization

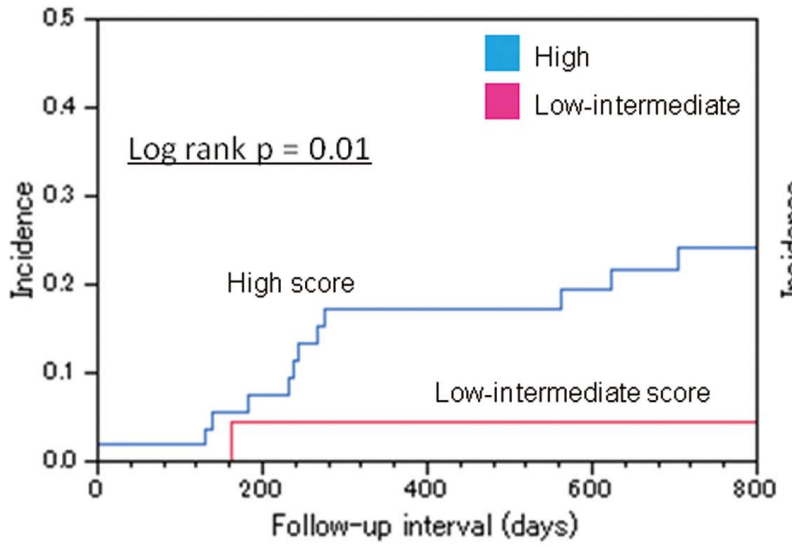

$\begin{array}{lccc}\text { High score } & \text { baseline } & \text { 1 year } & \text { 2 years } \\ \text { Incidence } & & 17.1 \% & 24.3 \% \\ \text { N of events } & & 9 & 12 \\ \text { N of patients at risk } & 55 & 43 & 30 \\ \text { Low-intermediate score } & & & \\ \text { Incidence } & & 4.4 \% & 4.4 \% \\ \mathrm{~N} \text { of events } & 46 & 2 & 2 \\ \mathrm{~N} \text { of patients at risk } & 42 & 30\end{array}$

\section{B Any Revascularization}

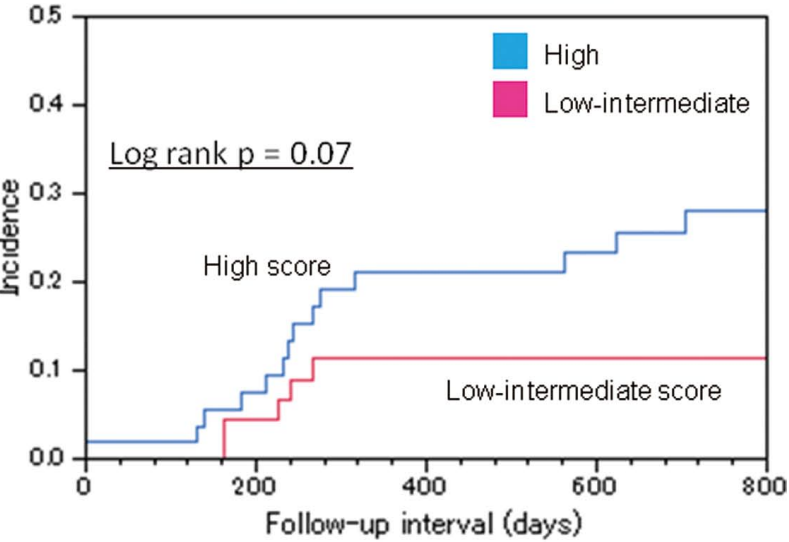

$\begin{array}{lccc}\text { High score } & \text { baseline } & \text { 1 year } & \text { 2 years } \\ \text { Incidence } & & 21.0 \% & 28.2 \% \\ \text { N of events } & 55 & 11 & 14 \\ \text { N of patients at risk } & 41 & 29 \\ \text { Low-intermediate score } & & & \\ \text { Incidence } & & 11.3 \% & 11.3 \% \\ N \text { of events } & 46 & 59 & 5 \\ N \text { of patients at risk } & 46 & 28\end{array}$

Figure 3. Unadjusted Kaplan-Meier curves for cumulative incidence of target lesion revascularization (A) and any revascularization (B) between the low-intermediate score group and high score group.

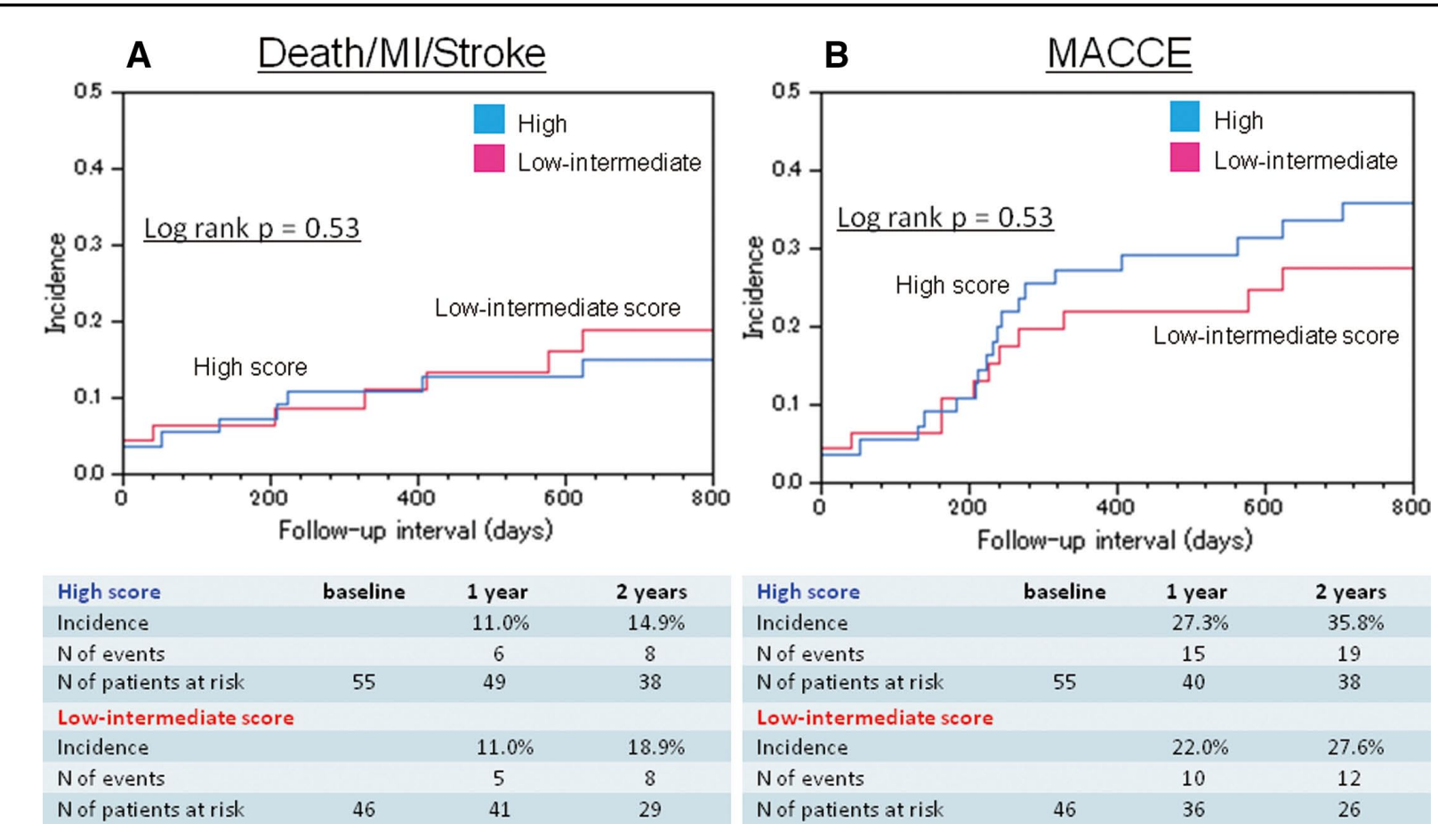

Figure 4. Unadjusted Kaplan-Meier curves for cumulative incidence of death, MI, or stroke (A) and MACCE (B) between the low-intermediate score group and high score group. MI, myocardial infarction; MACCE, major adverse cardiac and cerebrovascular events. 
$\mathrm{P}=0.26$, respectively) (Figure 2; Table 4). The incidence of TLR was significantly higher in the high score group than in the low-intermediate score group $(24.3 \%$ vs. $4.4 \%, \mathrm{P}=0.01$, respectively) (Figure 3A). The incidence of any revascularization tended to be higher in the high score group than in the low-intermediate group $(28.2 \%$ vs. $11.3 \%, \mathrm{P}=0.07$, respectively) (Figure 3B). The incidences of a composite of death, MI, or stroke, and MACCE were not different between the low-intermediate score group and the high score group ( $18.9 \%$ vs. $14.9 \%, \mathrm{P}=0.53$ and $27.6 \%$ vs. $35.8 \%, \mathrm{P}=0.53$, respectively) (Figure 4).

\section{Discussion}

The main findings in the present study are as follows: (1) both inter- and intra-observer variability for estimating the SYNTAX score were within the acceptable range in patients undergoing ULMCA stenting in daily clinical practice; and (2) the incidence of TLR was significantly higher in the high SYNTAX score group than in the low-intermediate SYNTAX score group.

\section{Reproducibility of Estimation for the SYNTAX Score}

Both inter- and intra-observer variability for estimation of the SYNTAX score in the present study indicated a moderate to substantial degree of agreement beyond chance (the $\kappa$ value of inter- and intra-observer variability: 0.62 , and 0.78 , respectively). The degree of agreement in the current analysis in real world clinical practice was consistent with previous results evaluating the SYNTAX score variability in patients enrolled in SYNTAX trial. ${ }^{15,16}$

Contrary to a previous report suggesting poor reproducibility of estimation of the SYNTAX score in patients with ULMCA disease, ${ }^{16}$ the agreement for estimation of the SYNTAX score in the present study was revealed to be of a moderate to substantial degree. One of the reasons why we could obtain such a result was that the analysis was performed retrospectively on the premise that the significant stenosis existed in the left main coronary artery, although observers were blinded to the procedural results and clinical outcomes. Indeed, angiographic evaluation of the significance of the intermediate stenosis in the left main coronary artery was reported to be more difficult compared with lesions in other locations, although the impact of the decision is clinically greater in left main coronary artery lesions. ${ }^{17-19}$

The present study also evaluated the variability for estimation of the components of scoring, such as the presence of true bifurcation or long lesion in the ULMCA lesions. As shown in Table 2, the reproducibility of estimation for the components of scoring was relatively poor compared with that for the total SYNTAX score. This result highlighted the difficulty in assessing individual components of scoring reproducibility as suggested by previous studies. ${ }^{20,21}$ However, the total extent of atherosclerotic changes and anatomic complexities, which were reflected by the total SYNTAX score, would be more predictive of clinical outcomes after PCI than the individual components of scoring. A moderate to substantial degree of agreement for the total SYNTAX score would provide support for clinical applicability of the SYNTAX score.

\section{Association of the SYNTAX Score With Clinical Outcomes}

In the SYNTAX trial, there were incremental differences between PCI and CABG in the incidences of MACCE as the SYNTAX score increased. ${ }^{6}$ In a sub-analysis of left main disease in the SYNTAX trial, the patients undergoing PCI had a significantly higher rate of MACCE compared with the patients receiving CABG in patients with a high SYNTAX score ( $\geq 33$ ), but not in those with a low-intermediate score. ${ }^{22}$ Capodanno et al reported that a higher SYNTAX score was significantly associated with cardiac mortality and MACE in 255 patients who underwent PCI for left main disease in a single center. ${ }^{23}$ The same group of investigators also reported that PCI resulted in a similar risk of 2-year mortality compared with CABG in patients with a SYNTAX score of $\leq 34$ and in a significantly higher risk in patients with a SYNTAX score of $>34$ in 819 patients with left main disease undergoing revascularization in 2 Italian centers. ${ }^{24}$

In the present study, we made an exploratory analysis for the correlation between the SYNTAX score and clinical outcomes. There was no significant difference between the 2 groups not only in all-cause death or cardiac death, but also in the composite endpoints such as MACCE. On the other hand, the incidence of TLR in the high score group was significantly higher compared to the low-intermediate score group. Also, the trend for a higher incidence of any coronary revascularization was consistent with the result from the SYNTAX trial. Obviously, the present analysis was not able to evaluate the incidence of death or cardiac death. Future studies with adequate statistical power would be needed to elucidate the correlation between the SYNTAX score and mortality after ULMCA stenting.

\section{Study Limitations}

The present study has several important limitations. First, as already mentioned, variability for the assessment of the SYNTAX score was retrospectively evaluated in a population with a known history of ULMCA stenting. Therefore, it would not be appropriate to extrapolate the current result to the broader patient population with severe coronary disease without ULMCA disease. Second, the reproducibility for assessing the SYNTAX score would be profoundly influenced by the experiences in SYNTAX score calculation and the efforts to reach the consensus between the observers before actual calculation. Finally, the study was limited by the retrospective single center study. The sample size was too small to evaluate clinical endpoints and no adjustment was made for the clinical characteristics.

\section{Conclusions}

Both inter- and intra-variability for estimating the SYNTAX score were acceptable and a high SYNTAX score showed a higher rate of TLR in patients who underwent ULMCA stenting in daily clinical practice.

\section{Disclosures}

Conflict of interest: Takeshi Kimura is an advisory board member, speaker, and recipient of research grants from Cordis Cardiology Japan, Johnson and Johnson. The remaining authors reported no conflicts.

\section{References}

1. Vaquerizo B, Lefevre T, Darremont O, Silvestri M, Louvard Y, Leymarie JL, et al. Unprotected left main stenting in the real world: Two-year outcomes of the French left main taxus registry. Circulation 2009; 119: 2349-2356.

2. Toyofuku M, Kimura T, Morimoto T, Hayashi Y, Ueda H, Kawai $\mathrm{K}$, et al. Three-year outcomes after sirolimus-eluting stent implantation for unprotected left main coronary artery disease: Insights from the j-Cypher registry. Circulation 2009; 120: 1866-1874.

3. Kim YH, Park DW, Lee SW, Yun SC, Lee CW, Hong MK, et al. 
Long-term safety and effectiveness of unprotected left main coronary stenting with drug-eluting stents compared with bare-metal stents. Circulation 2009; 120: 400-407.

4. Buszman PE, Buszman PP, Kiesz RS, Bochenek A, Trela B, Konkolewska M, et al. Early and long-term results of unprotected left main coronary artery stenting: The LE MANS (Left Main Coronary Artery Stenting) registry. J Am Coll Cardiol 2009; 54: 15001511.

5. Seung KB, Park DW, Kim YH, Lee SW, Lee CW, Hong MK, et al. Stents versus coronary-artery bypass grafting for left main coronary artery disease. $N$ Engl J Med 2008; 358: 1781-1792.

6. Cheng CI, Lee FY, Chang JP, Hsueh SK, Hsieh YK, Fang CY, et al. Long-term outcomes of intervention for unprotected left main coronary artery stenosis: Coronary stenting vs coronary artery bypass grafting. Circ J 2009; 73: 705-712.

7. Hsueh SK, Wu CJ, Fang HY, Hsieh YK, Fang CY, Chen CJ, et al. Comparison of drug-eluting stent with bare metal stent for distal de novo unprotected left main coronary artery stenosis. Circ J 2011; 75: $290-298$.

8. Serruys PW, Morice MC, Kappetein AP, Colombo A, Holmes DR, Mack MJ, et al. Percutaneous coronary intervention versus coronary-artery bypass grafting for severe coronary artery disease. $N$ Engl J Med 2009; 360: 961-972.

9. Sianos G, Morel MA, Kappetein AP, Morice MC, Colombo A, Dawkins K, et al. The SYNTAX Score: An angiographic tool grading the complexity of coronary artery disease. EuroIntervention 2005; 1: 219-227.

10. Serruys PW, Unger F, Sousa JE, Jatene A, Bonnier HJ, Schonberger JP, et al. Comparison of coronary-artery bypass surgery and stenting for the treatment of multivessel disease. $N$ Engl $J$ Med 2001; 344: 1117-1124.

11. Cutlip DE, Windecker S, Mehran R, Boam A, Cohen DJ, van Es GA, et al. Clinical end points in coronary stent trials: A case for standardized definitions. Circulation 2007; 115: 2344-2351.

12. Viera AJ, Garrett JM. Understanding interobserver agreement: The kappa statistic. Fam Med 2005; 37: 360-363.

13. Landis JR, Koch GG. The measurement of observer agreement for categorical data. Biometrics 1977; 33: 159-174.

14. Fleiss J. Statistical methods for rates and proportions. New York: John Wiley \& Sons Inc; 1981.

15. Serruys PW, Onuma Y, Garg S, Sarno G, van den Brand M, Kappetein AP, et al. Assessment of the SYNTAX score in the
Syntax study. EuroIntervention 2009; 5: 50-56.

16. Garg S, Girasis C, Sarno G, Goedhart D, Morel MA, Garcia-Garcia HM, et al. The SYNTAX score revisited: A reassessment of the SYNTAX score reproducibility. Catheter Cardiovasc Interv 2010; 75: $946-952$.

17. Lindstaedt M, Spiecker M, Perings C, Lawo T, Yazar A, HollandLetz T, et al. How good are experienced interventional cardiologists at predicting the functional significance of intermediate or equivocal left main coronary artery stenoses? Int J Cardiol 2007; 120: $254-261$.

18. Fisher LD, Judkins MP, Lesperance J, Cameron A, Swaye P, Ryan $\mathrm{T}$, et al. Reproducibility of coronary arteriographic reading in the coronary artery surgery study (CASS). Cathet Cardiovasc Diagn 1982; 8: $565-575$.

19. Hamilos M, Muller O, Cuisset T, Ntalianis A, Chlouverakis G, Sarno G, et al. Long-term clinical outcome after fractional flow reserve-guided treatment in patients with angiographically equivocal left main coronary artery stenosis. Circulation 2009; 120: $1505-$ 1512 .

20. Beauman GJ, Vogel RA. Accuracy of individual and panel visual interpretations of coronary arteriograms: Implications for clinical decisions. J Am Coll Cardiol 1990; 16: 108-113.

21. Herrman JP, Azar A, Umans VA, Boersma E, von Es GA, Serruys $\mathrm{PW}$. Inter- and intra-observer variability in the qualitative categorization of coronary angiograms. Int J Card Imaging 1996; 12: $21-30$.

22. Morice MC, Serruys PW, Kappetein AP, Feldman TE, Stahle E, Colombo A, et al. Outcomes in patients with de novo left main disease treated with either percutaneous coronary intervention using paclitaxel-eluting stents or coronary artery bypass graft treatment in the Synergy Between Percutaneous Coronary Intervention with TAXUS and Cardiac Surgery (SYNTAX) trial. Circulation 2010; 121: $2645-2653$.

23. Capodanno D, Di Salvo ME, Cincotta G, Miano M, Tamburino C, Tamburino C. Usefulness of the SYNTAX score for predicting clinical outcome after percutaneous coronary intervention of unprotected left main coronary artery disease. Circ Cardiovasc Interv 2009; 2: $302-308$.

24. Capodanno D, Capranzano P, Di Salvo ME, Caggegi A, Tomasello $\mathrm{D}$, Cincotta G, et al. Usefulness of SYNTAX score to select patients with left main coronary artery disease to be treated with coronary artery bypass graft. JACC Cardiovasc Interv 2009; 2: 731-738. 